\title{
ОТНОСИТЕЛЬНЫЕ ВРЕМЕНА УДЕРЖИВАНИЯ УГЛЕВОДОРОДОВ В ГАЗОХРОМАТОГРАФИЧЕСКОМ АНАЛИЗЕ *
}

\author{
Ю. ЭЙЗЕН
}

\author{
Л. КУДРЯВЦЕВА, С. РАНГ, \\ кандидаты химических наук \\ О. ЭЙЗЕН, \\ кандидат технических наук
}

Под тривиальным названием твинов поступили в продажу высокомолекулярные полярные термически устойчивые соединения, структура которых содержит группировку полиоксиэтилен-сорбитана, и номер которых соответствует раднкалу кислоты. Например, полиоксиэтиленсорбитанмонолаурат носит название твин 20 , а полиоксиэти-ленсорбитантриолеат - твин 85.

В зарубежной литературе появились данные об. использовании твинов в качестве стационарных жидких фаз з газовой хроматографии. Согласно этим данным, прнменение твина 80 и твина 60 разрешается до температуры $200^{\circ} \mathrm{C}$. Их рекомендуют особенно для анализа ароматических и олефиновых углеводородов. До сих пор, однако, отсутствуют-систематические данные о временах удерживания углеводородов при использовании твинов в качестве жидкой фазы, а также сравнительная характеристика твинов при анализе углеводородов.

В настоящей работе приводятся некоторые данные об относительных временах удерживания углеводородов на твинах $20,40,60,80,85$, полученных от фирмы «Gee Lawson». Характеристика применявшихся колонок приведена в табл. 1. Другие условия эксперимента опубликованы ранее [1].

В табл. 2 приведены относительные времена удерживания исследованных углеводородов. Время удерживания бензола было принято за 100

По данным, приведенным в табл. 2, можно сделать ряд заключений о твинах как о стационарных фазах.

Таблица 1

Характеристика колонок, применявшихся при определении относительных времен удерживания углеводородов

\begin{tabular}{|c|c|c|c|c|c|}
\hline Колонка & Твин 20 & Твин 40 & Твин 60 & Твин 80 & Твин 85 \\
\hline Химический состав & $\begin{array}{c}\text { Полиокси- } \\
\text { этилен- } \\
\text { сорбитан- } \\
\text { монолаурат }\end{array}$ & $\begin{array}{l}\text { Полиокси- } \\
\text { этилен- } \\
\text { сорбитан- } \\
\text { монопаль- } \\
\text { митат }\end{array}$ & $\begin{array}{c}\text { Полиокси- } \\
\text { этилен- } \\
\text { сорбитан- } \\
\text { моностеарат }\end{array}$ & $\begin{array}{l}\text { Полиокси- } \\
\text { этилен- } \\
\text { сорбитан- } \\
\text { моноолеат }\end{array}$ & $\begin{array}{l}\text { Полиокси- } \\
\text { этилен- } \\
\text { сорбитан- } \\
\text { триолеат }\end{array}$ \\
\hline $\begin{array}{l}\text { Количество жид- } \\
\text { кой фазы, \% } \\
\text { Твердая фаза, мм }\end{array}$ & 20 & $\begin{array}{l}20 \\
\text { Диатоми }\end{array}$ & $\begin{array}{c}20 \\
\text { овый кирпич }\end{array}$ & $0,20 \stackrel{20}{-} 0,25$ & 20 \\
\hline $\begin{array}{l}\text { Длина колонки, } M \\
\text { Внутренний } \\
\text { диа. }\end{array}$ & 3 & 3 & 3 & 3 & 3 \\
\hline $\begin{array}{l}\text { метр колонки, мм } \\
\text { Число теоретиче- } \\
\text { ских тарелок при }\end{array}$ & 4 & 4 & 4 & 4 & 4 \\
\hline $\begin{array}{l}150^{\circ} \text { по толуолу } \\
\text { Газ-носитель }\end{array}$ & $\begin{array}{c}1700 \\
\mathrm{H}_{2}\end{array}$ & $\begin{array}{c}1900 \\
\mathrm{H}_{2}\end{array}$ & $\begin{array}{c}1500 \\
\mathrm{H}_{2}\end{array}$ & $\begin{array}{c}1300 \\
\mathrm{H}_{2}\end{array}$ & $\begin{array}{l}1700 \\
\mathrm{H}_{2}\end{array}$ \\
\hline
\end{tabular}

* Продолжение сообщения, опубликованного в Изв. АН ЭССР. Сер. физ.-матем и техн. наук, 1964, № 1 . 


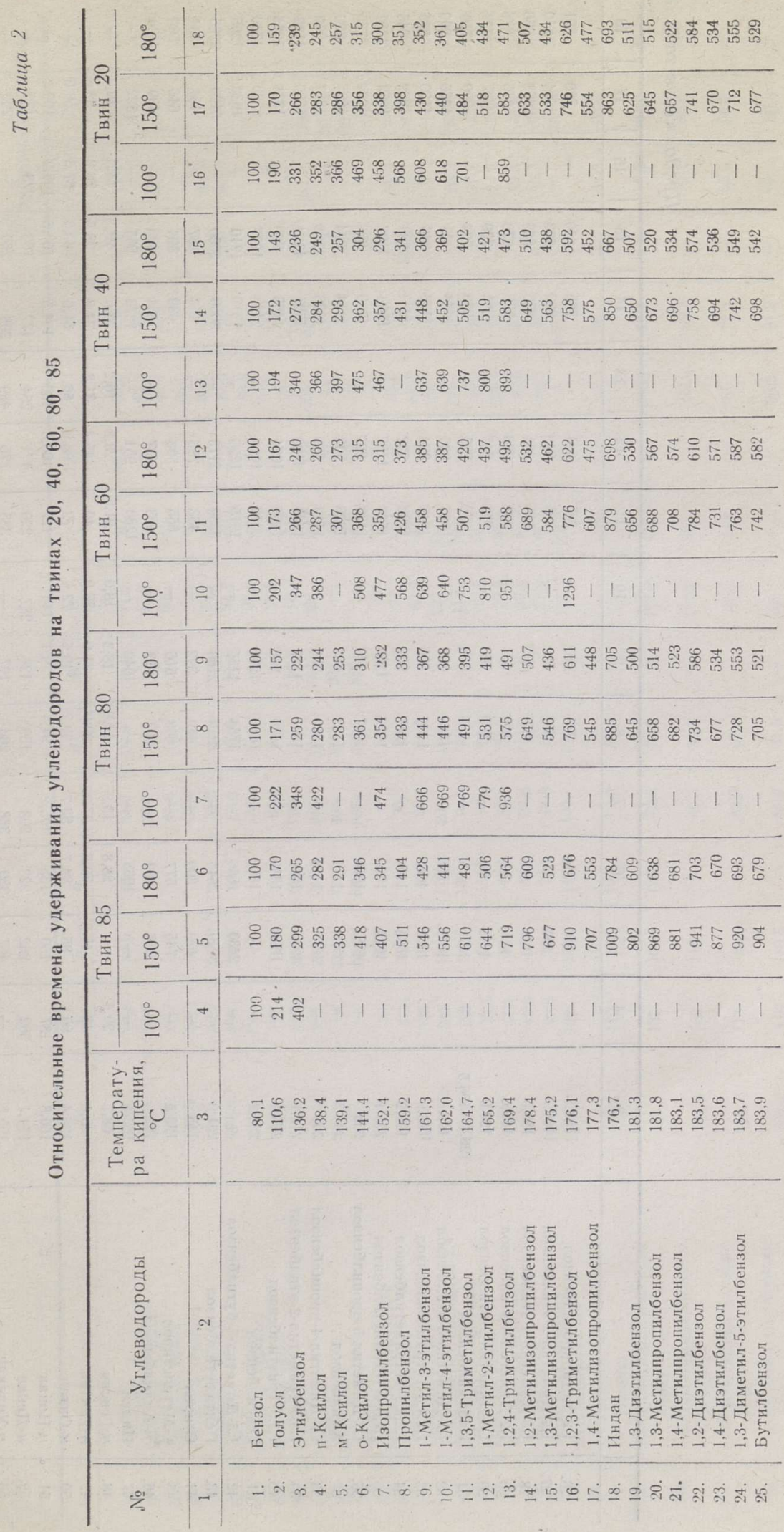




\begin{tabular}{|c|c|}
\hline$\stackrel{\infty}{1}$ & 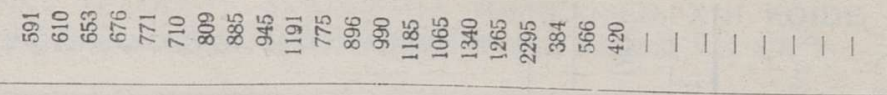 \\
\hline$=$ & 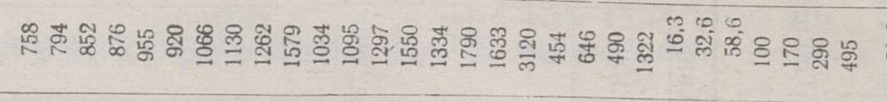 \\
\hline$\underline{0}$ & 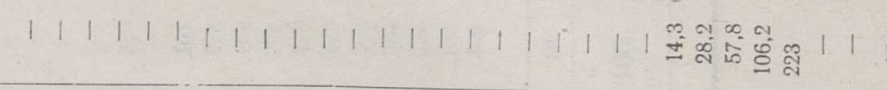 \\
\hline$\stackrel{2}{2}$ & 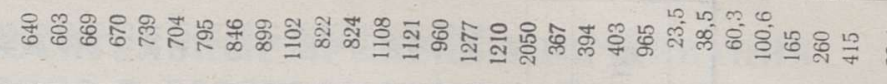 \\
\hline$\Xi$ & 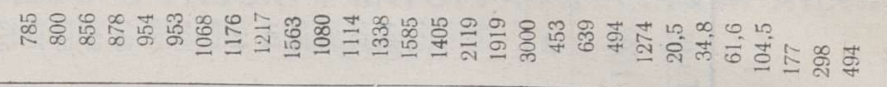 \\
\hline$\cong$ & 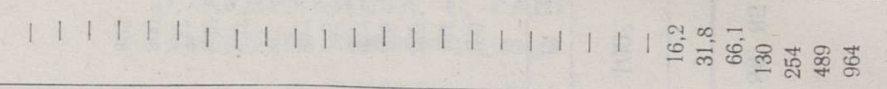 \\
\hline$\cong$ & 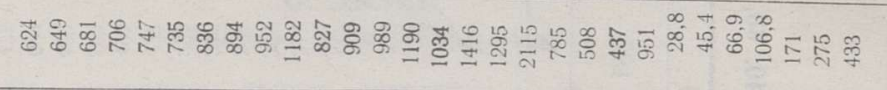 \\
\hline$=$ & 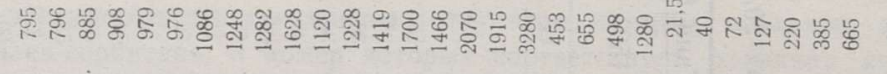 \\
\hline 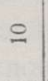 & 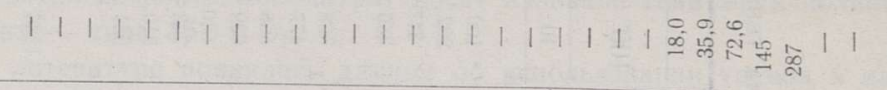 \\
\hline a & 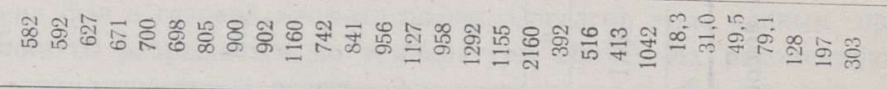 \\
\hline$\infty$ & 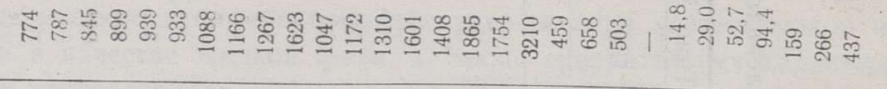 \\
\hline - & 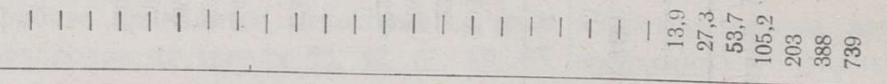 \\
\hline$\bullet$ & 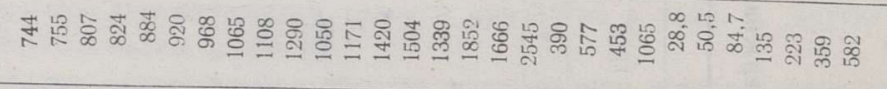 \\
\hline is & 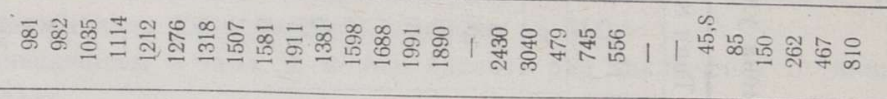 \\
\hline+ & 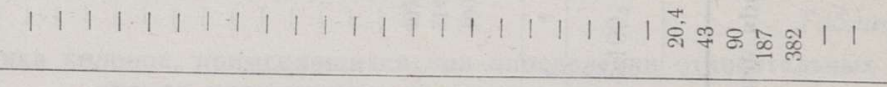 \\
\hline$\infty$ & 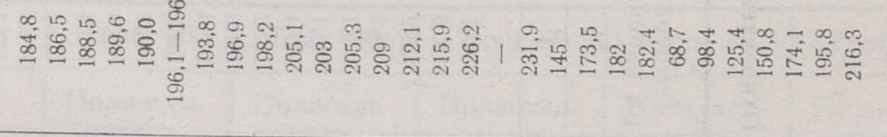 \\
\hline 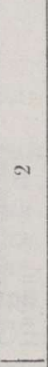 & 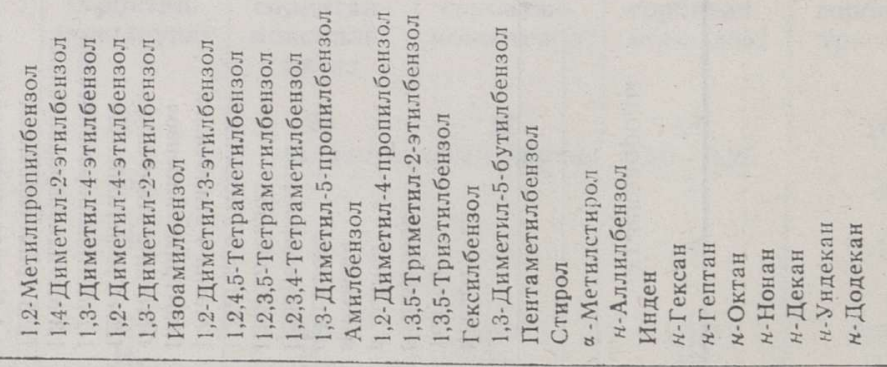 \\
\hline- & वें \\
\hline
\end{tabular}


-1
5
8
0
0
0
0
0
0
0
0
0
5

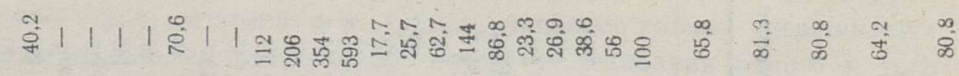

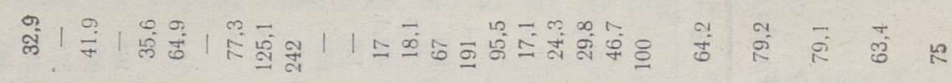

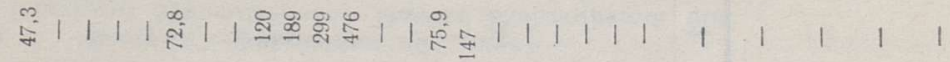

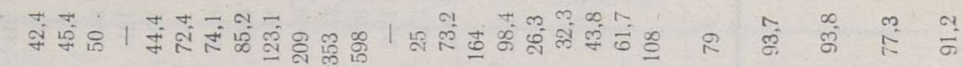

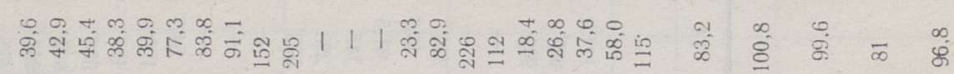

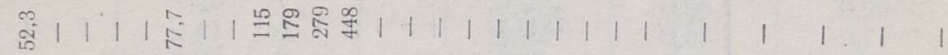

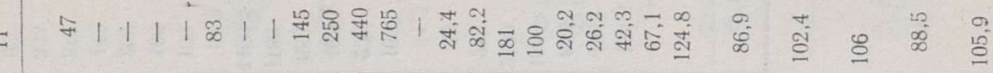

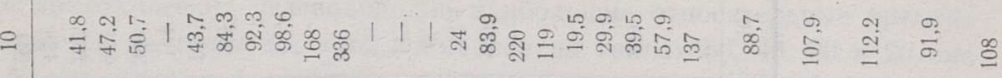

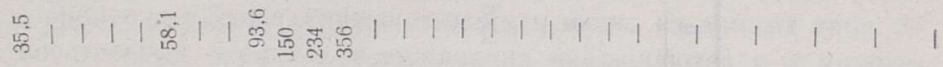

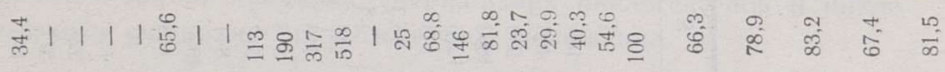

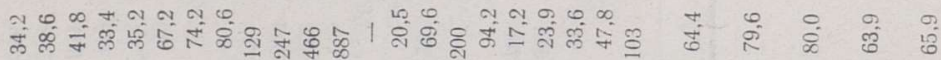

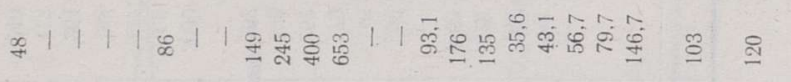

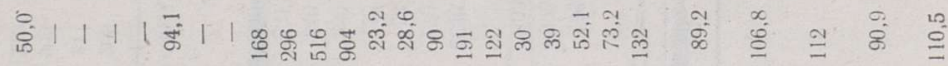

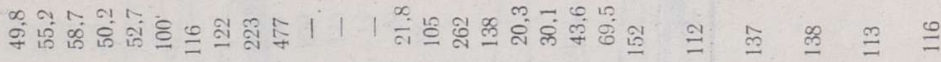

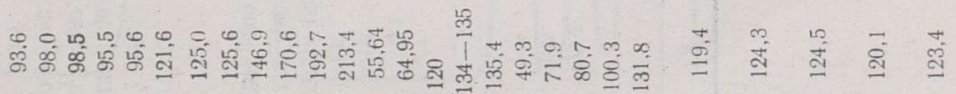

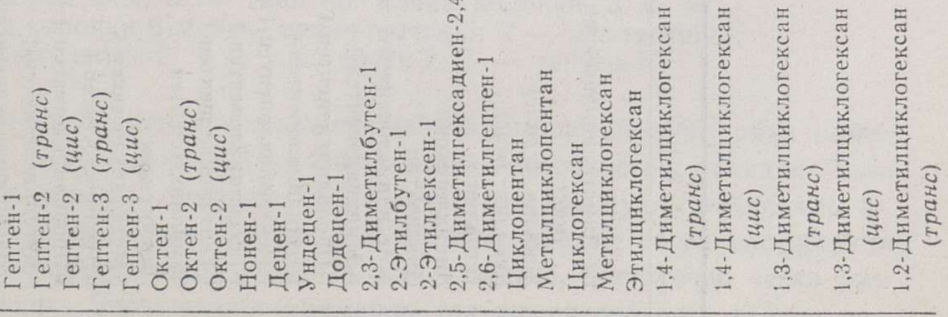

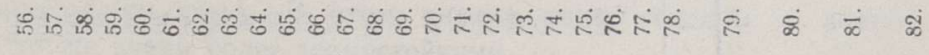




\begin{tabular}{|c|c|}
\hline 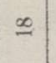 & 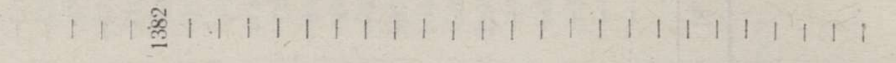 \\
\hline$=$ & 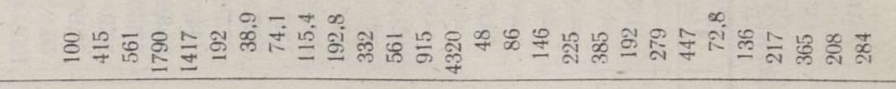 \\
\hline 9 & 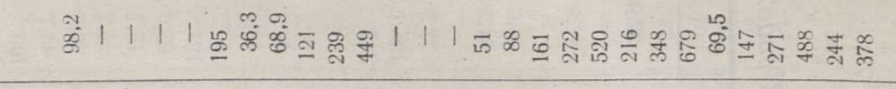 \\
\hline$\stackrel{2}{2}$ & $11101011+11111111111111111111$ \\
\hline \pm & 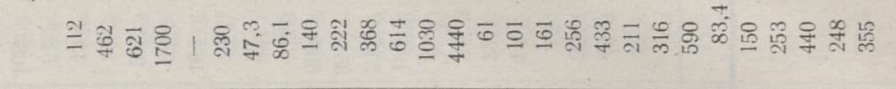 \\
\hline$\cong$ & 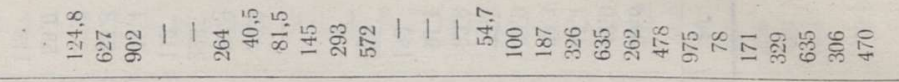 \\
\hline$\cong$ & 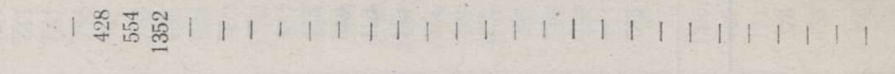 \\
\hline$=$ & 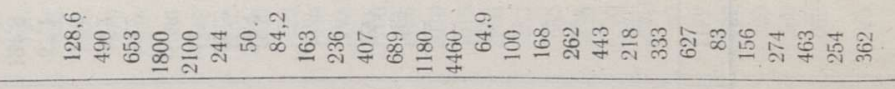 \\
\hline 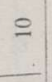 & 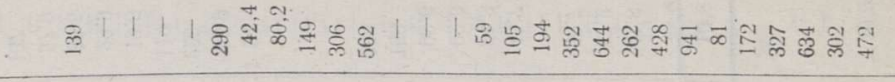 \\
\hline$\circ$ & 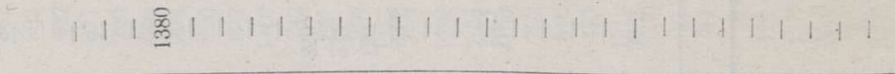 \\
\hline$\infty$ & 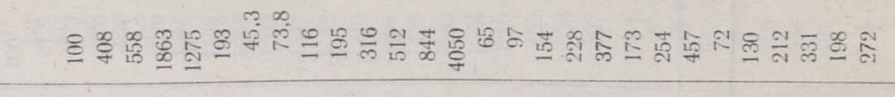 \\
\hline- & 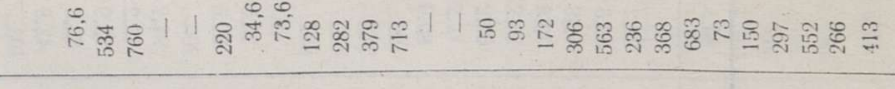 \\
\hline$\bullet$ & 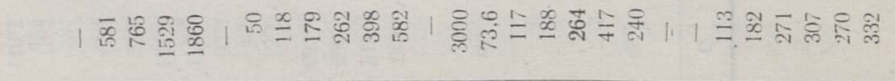 \\
\hline$\therefore$ & 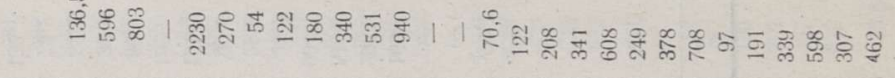 \\
\hline+ & 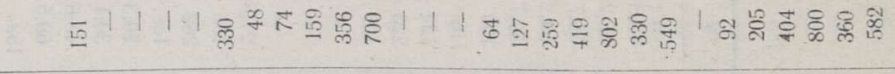 \\
\hline$\infty$ & 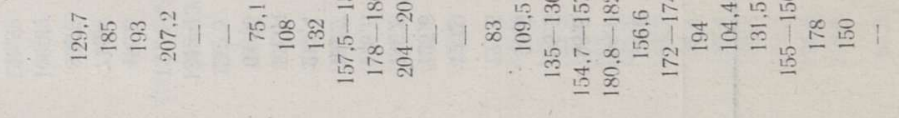 \\
\hline$\sim$ & 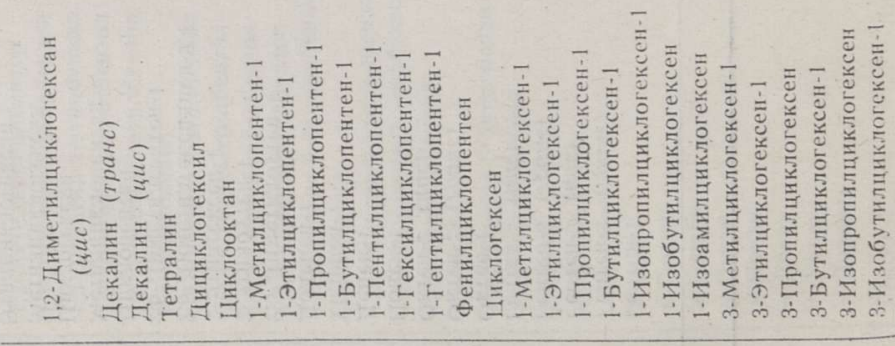 \\
\hline- & 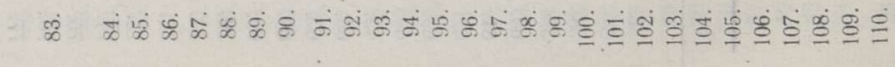 \\
\hline
\end{tabular}


Из сравнения времен удерживания углеводородов на различных твннах следует, что один и тот же углеводород, независимо от группы, наиболее снльно удерживается на твине 85 и наименее сильно - на твине 20. Времія удерживания одного н того же углеводорода уменьнается в ряду твинов $85,60,40,80,20$ (см. табл. 3).

Таблица 3

\section{Средние различия относительных времен удерживания при хроматографировании на твинах}

(3а 1 принято время удерживания на твине б0)

\begin{tabular}{|c|c|c|c|c|c|}
\hline $\begin{array}{l}\text { Группа углеводородов и } \\
\text { температура колонки, }{ }^{\circ} \mathrm{C}\end{array}$ & Твин 85 & Твин 60 & Твин 40 & Твин 80 & Твин 20 \\
\hline $\begin{array}{l}\text { Ароматические углеводоро- } \\
\text { ды, } 150 \\
\text { н-1-Олефины, } 100 \\
\text { Циклогексены, } 100 \\
\text { Циклопентены, } 100 \\
\text { н-Парафины, } 100\end{array}$ & $\begin{array}{l}1,20 \\
1,41 \\
1,23 \\
1,33 \\
1,49\end{array}$ & $\begin{array}{l}1 \\
1 \\
1 \\
1 \\
1\end{array}$ & $\begin{array}{l}0,97 \\
0,92 \\
0,95 \\
0,99 \\
0,89\end{array}$ & $\begin{array}{l}0,96 \\
0,83 \\
0,88 \\
0,90 \\
0,81\end{array}$ & $\begin{array}{l}0,95 \\
0,77 \\
0,87 \\
0,88 \\
0,78\end{array}$ \\
\hline
\end{tabular}

При разделении ароматических углеводородов наибольшіе относительные времена удерживания оказываются на твине 85, в то время как на твинах $60,40,80$ и 20 они гочти одинаковы. У нормальных 1-олефинсв, по сравнению с ароматическими углеводородами, различия во временах удерживания больше, как вндно из данных табл. 3 . Большие различия в относительных временах удерживания наблюдаются и у $\boldsymbol{H}$-парафиновых углеводородов. Разлкчия во временах удерживания циклогексенов н цикло. пентенов на указанных твинах занимают промежуточное положение.

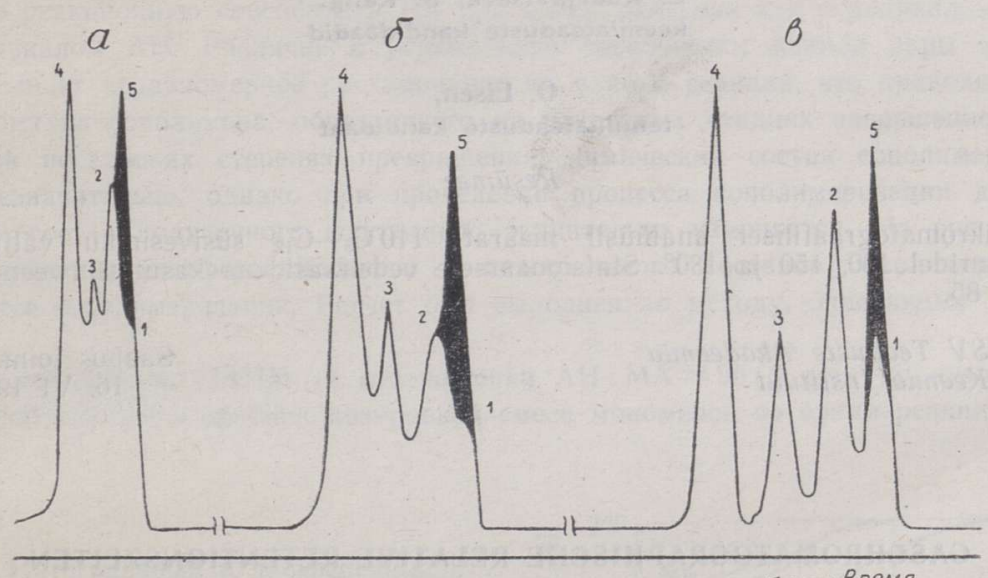

Хроматограммы изомерных гептеновых углеводородов: $a-$ твин 40 , длина колонки 3 ; б - твин 85 , длина колонки 3 ж; втвин 85 , длина колонки 6 м. 1 - транс-гептен-3; 2 - цис-гептен-3; 3 - транс-гептен- $2 ; 4$ - цис-гептен-2; 5 - гептен-1.

Из сравнения отношений времен удерживания членов гомологического ряда $\boldsymbol{H}$-олефинов на твинах следует, что нанбольшей удерживающей способностью обладает твин 85. Способность твинов разделять олефины превышает разделяющую способность $\beta$-, $\beta^{\prime}$-тиодипропионитрила и полигликоля. Твины 60 и 85 отвечают, по своей способности разделять олефины, дифенилформамиду, который, как известно, достаточно четко раз. деляет олефины и парафины. Заслуживает внимания так же способность твинов разделять цис- и транс-изомеры (см. рис.). В этом смысле твины сходны с ацетонилацетоном, являясь в то же время более термостойкими. 
Из сравнения данных о временах удерживания ароматических углеводородов на твинах, с одной стороны, и на $\beta$-, $\beta^{\prime}$-тиодипропионитриле или полигликоле, с другой стороны, следует, что по способности разделять ароматическне углеводороды твины не уступают названным жидким фазам.

На основе нашего опыта можно сказать, что твины достаточно стабильны по отношению к нагреванию. Так, например, твин 80 дает возможность проводить анализ длительное время при $150^{\circ}$ и более короткое время при $180^{\circ}$ без заметных изменений в значениях относительных времен удерживания.

Твины являются универсальными газохроматографическими жидкими фазами н особенно пригодны для разделения олефиновых углеводородов.

\title{
Л ИТЕ Р А Т У Р A
}

1. Эйз ен Ю. И., Кир рет О. Г., Эй зен О. Г., Изв. АН ЭССР, Сер. физ.-матем. и техн, наук, 13, № 1,23 (1964).

Ннститут химии

Академии наук Эстонской ССР
Поступила в редакцию

16. VI 1964

\section{SUSIVESINIKE SUHTELISTEST VALJUMISAEGADEST GAASIKROMATOGRAAFILISEL ANALUUSIL}

\author{
J. Eisen
}

L. Kudrjavtseva, S. Rang, keemiateaduste kandidaadid

0. Eisen,

tehnikateaduste kandidaat

Resümee

Gaasikromatograafilisel analüüsil määrati $110 \mathrm{C}_{5}-\mathrm{C}_{12}$ süsivesiniku väljumisajad temperatuuridel 100,150 ja $180^{\circ}$. Statsionaarsete vedelfaasidena kasutati tweene 20,40 , 60,80 ja 85 .

Eesti NSV Teaduste Akadeemia Keemia Instituut
Saabus toimetusse

16. VI 1964

\section{GASCHROMATOGRAPHISCHE RELATIVE RETENTIONSZEITEN DER KOHLENWASSERSTOFFE}

J. Eisen, L. Kudrjavtseva, S. Rang, 0. Eisen

\section{Zusammenfassung}

Es wurden gaschromatographische relative Retentionszeiten für den $110 \mathrm{C}_{5}-\mathrm{C}_{12}$ Kohlenwasserstoff bestimmt. Als flüssige Phase dienten Tween 20, Tween 40, Tween 60 , Tween 80 und Tween 85 .

Eingegangen am 16. Juni 1964 